\title{
Contact Resistance Comparison of Flip-Chip Joints Produced with Anisotropic Conductive Adhesive and Nonconductive Adhesive for Smart Textile Applications
}

\author{
Jung-Yeol Choi* and Tae Sung Oh \\ Department of Materials Science and Engineering, Hongik University, \\ Seoul 121-791, Republic of Korea
}

For applications in smart textiles, flip-chip bonding was applied with either an anisotropic conductive adhesive (ACA) or a nonconductive adhesive (NCA) to a heat-resistant fabric and a Si substrate as a reference. The average contact resistances of the flip-chip joints produced with each adhesive on each substrate were evaluated with varying the $\mathrm{Cu}$ and $\mathrm{Sn}$ thicknesses inversely over the range of $0-15 \mu \mathrm{m}$ to maintain a total thickness of $15 \mu \mathrm{m}$ of the $\mathrm{Cu} / \mathrm{Sn}$ bump. The contact resistances of the flip-chip joints produced with ACA on $\mathrm{Si}, \mathrm{NCA}$ on $\mathrm{Si}, \mathrm{ACA}$ on fabric, and NCA on fabric were 6.5-12.2 $\mathrm{m} \Omega, 15.6-26.5 \mathrm{~m} \Omega, 5.3-10.2 \mathrm{~m} \Omega$, and 5.5-10.1 m $\Omega$, respectively. [doi:10.2320/matertrans.M2015106]

(Received March 12, 2015; Accepted July 30, 2015; Published September 11, 2015)

Keywords: wearable electronics, smart textile, flip chip, contact resistance, fabric

\section{Introduction}

Smart textiles, which are also referred to as electronic textiles (e-textiles), have been investigated to allow useful functions of information and communication technology (ICT) in textiles for advanced wearable device applications, such as ubiquitous health monitoring and child care. ${ }^{1-8)}$ To ensure aesthetical acceptability, comfortable wearability, and sufficient functionality for smart textiles, recent studies have focused on unobtrusively integrating electronic components and sensors into fabric by embedding electronic components into a fabric circuit produced by embroidered interconnections and textile wiring of conductive threads. ${ }^{1-6,9)}$ Additionally, various efforts have been pursued in developing conductive yarn-based electrodes, antennas, and sensors to realize smart textiles integrated at the yarn level. ${ }^{2,9-13)}$

For proper function of smart textiles in processing signals detected by fabric sensors and communicating with the outside world, it is indispensable to mount semiconductor $\mathrm{Si}$ chips on the fabric and interconnect them to fabric circuits. Regarding chip mounting technology for smart textiles, various methods have been reported thus far: wire bonding of a chip to tiny metal plates inserted in punched holes of a fabric, ${ }^{14)}$ wire bonding of a chip to a screen-printed lead frame on a fabric, ${ }^{15)}$ and interconnection of a flexible board, where a chip is mounted to a fabric circuit using conductive threads. ${ }^{5)}$ Among them, wire bonding to tiny metal plates in a fabric ${ }^{14)}$ has disadvantages of poor adhesion between the metal plates and fabric, between the metal plates and metal cores of the conductive yarns, and between the metal plates and bonding wires. Using the wire bonding method with a screen-printed lead frame, ${ }^{15)}$ the electrical resistance of the lead frame is typically large, and open-circuit failure can easily occur due to cracking of the screen-printed lead frame from its solvent evaporation. However, the interconnection using a flexible board would have difficulty in electrically connecting the flexible board to a fabric circuit using conductive threads. ${ }^{5 \text { ) }}$

*Graduate Student, Hongik University
As an alternative chip mounting technology for smart textiles, we reported a flip-chip process using a nonconductive adhesive (NCA) to a $\mathrm{Cu}$ lead frame transferred onto a heat-resistant fabric in our previous work. ${ }^{8)}$ Our flipchip process has several advantages over other chip mounting methods; the adhesion between the fabric and transferred $\mathrm{Cu}$ lead frame is superior to that between fabric and tiny metal plates inserted in punched holes of the fabric. ${ }^{8,14)}$ The electrical resistance of the transferred $\mathrm{Cu}$ lead frame is low compared to that of a screen-printed lead frame. ${ }^{8,15)}$ In addition, flip-chip bonding has a strong potential to form a more compact package than one processed with wire bonding. ${ }^{8,14,15)}$ Though Kim et al. ${ }^{15)}$ mentioned the possibility of flip-chip bonding to screen-printed circuits on a fabric, actual contact-resistance data of flip-chip joints processed on a fabric cannot be found in literature with the exception of our previous work. ${ }^{8)}$

In our previous work, we used an NCA to mount a chip to the $\mathrm{Cu}$ lead frame on a fabric. ${ }^{8)}$ In terms of contact resistance, an anisotropic conductive film (ACF) and anisotropic conductive adhesive (ACA), which contain conductive particles, have been more commonly applied than a nonconductive film (NCF) and NCA for flip-chip processes on printed circuit boards and for chip-on-glass uses for flat panel displays. ${ }^{16-19)}$ In this study, we processed flip-chip bonding using ACA and NCA to a heat-resistant fabric and a Si substrate as a reference. We compared the average contact resistances of the flip-chip joints processed with each adhesive on each substrate to determine their effects on the contact resistance of the flip-chip joints.

\section{Experimental Procedure}

Figure 1 shows schematic illustrations of the daisy-chain configurations of a Si chip, $\mathrm{Cu}$ lead frame to be transferred to a fabric substrate, and $\mathrm{Ti} / \mathrm{Cu}$ metallization to be sputtered on a Si substrate. The fabrication procedure for a Si chip with dimensions of $6 \times 6 \mathrm{~mm}^{2}$ is illustrated in Fig. 2. A $0.1-\mu \mathrm{m}$ thick $\mathrm{Ti}$ and $2-\mu \mathrm{m}$ thick $\mathrm{Cu}$ were sequentially sputtered on a Si wafer, as shown in Fig. 2(a). After photoresist (PR) 


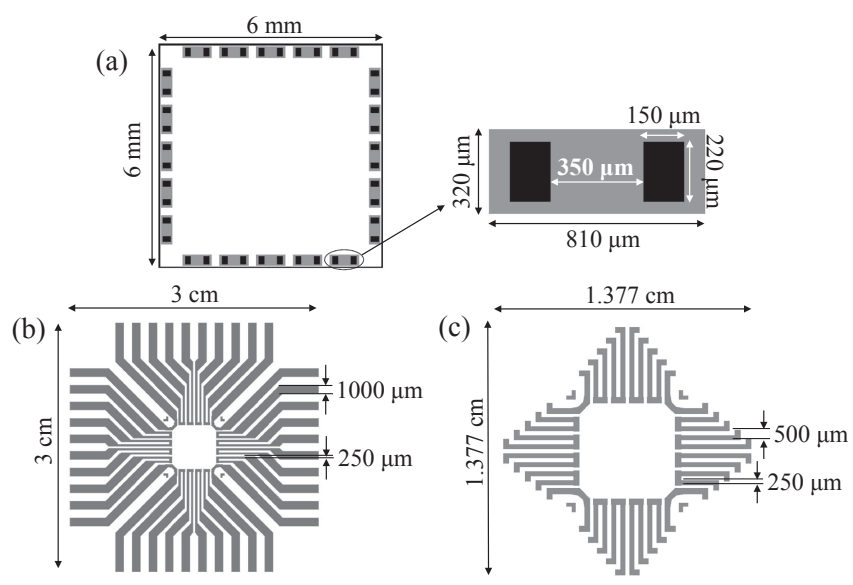

Fig. 1 Schematic illustrations of the daisy-chain configurations of a (a) $\mathrm{Si}$ chip, (b) $\mathrm{Cu}$ lead frame transferred to a fabric substrate, and (c) $\mathrm{Ti} / \mathrm{Cu}$ metallization sputtered on a Si substrate.
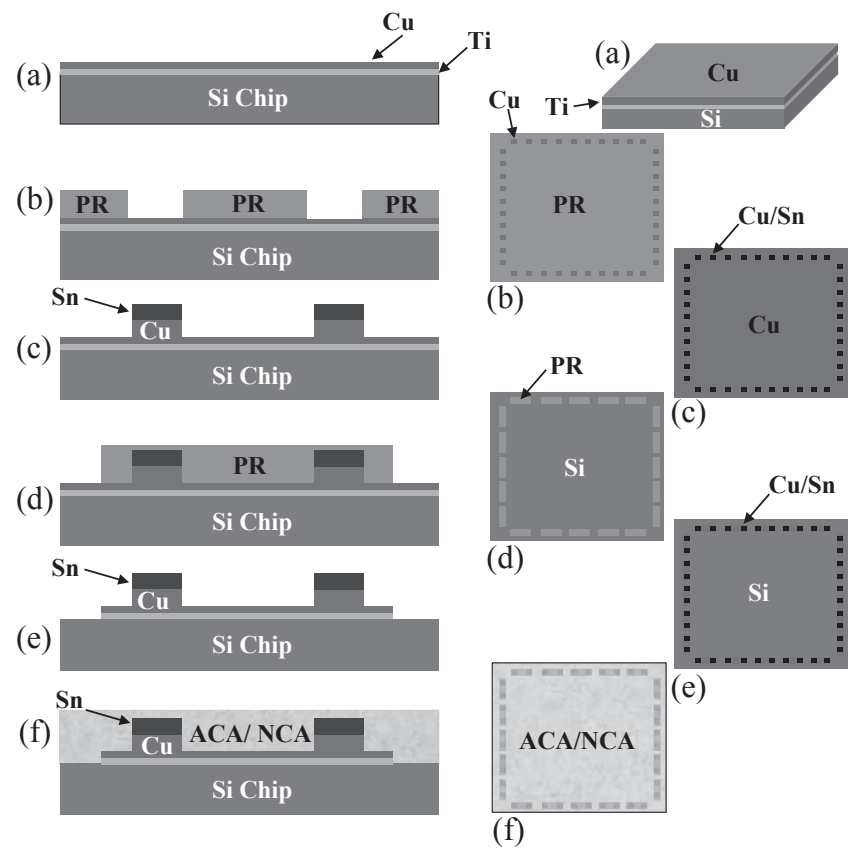

Fig. 2 Schematic illustrations of the fabrication process of a Si chip: (a) sputtering of $\mathrm{Ti} / \mathrm{Cu}$ metallization, (b) PR patterning, (c) electrodeposition of the $\mathrm{Cu} / \mathrm{Sn}$ bumps, (d) PR pattering, (e) formation of the bottom electrodes, (f) dispensing ACA or NCA for flip-chip bonding.

patterning, $\mathrm{Cu} / \mathrm{Sn}$ bumps with dimensions of $220 \times 150 \mu \mathrm{m}^{2}$ with a pitch of $500 \mu \mathrm{m}$ were formed on the $\mathrm{Cu}$ layer of the $\mathrm{Ti} / \mathrm{Cu}$ metallization with sequential $\mathrm{Cu}$ and $\mathrm{Sn}$ electrodeposition, as shown in Figs. 2(b) and (c). Cu electroplating was performed at a current density of $20 \mathrm{~mA} / \mathrm{cm}^{2}$ in a solution containing $98 \mathrm{~g} / \mathrm{L}$ of $\mathrm{CuSO}_{4} \cdot 5 \mathrm{H}_{2} \mathrm{O}, 98 \mathrm{~g} / \mathrm{L}$ of $\mathrm{H}_{2} \mathrm{SO}_{4}, 0.17 \mathrm{~g} / \mathrm{L}$ of $\mathrm{CuCl}_{2}, 0.3 \mathrm{~g} / \mathrm{L}$ of polyethylene glycol (PEG), and $10 \mathrm{ppm}$ of mercaptopropane sulfonic acid (MPS). Then, $\mathrm{Sn}$ was electrodeposited on top of the $\mathrm{Cu}$ using a commercial Sn-electroplating solution (Sloto Tin 41 of Hojin Platech Co., Ltd.) at a current density of $10 \mathrm{~mA} / \mathrm{cm}^{2}$. Each thickness of the electrodeposited $\mathrm{Cu}$ and $\mathrm{Sn}$ was controlled in the range of $0-15 \mu \mathrm{m}$ to ensure that the total thickness of a $\mathrm{Cu} / \mathrm{Sn}$ bump was $15 \mu \mathrm{m}$. As shown in Figs. 2(d) and (e), the $\mathrm{Ti} / \mathrm{Cu}$ metallization was etched off to form electrodes (a)

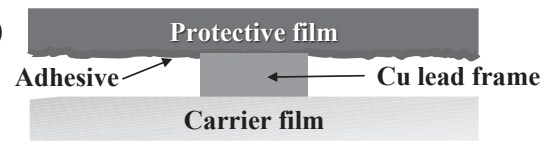

(b)
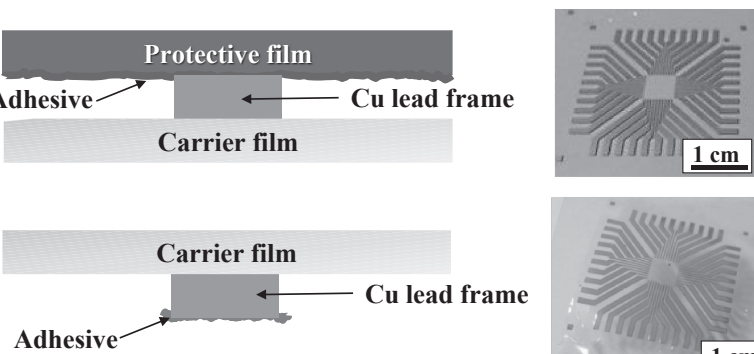

(c)

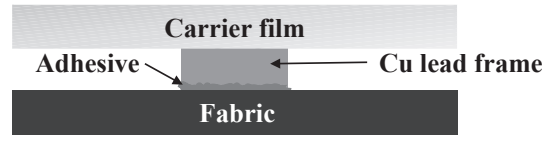

(d)
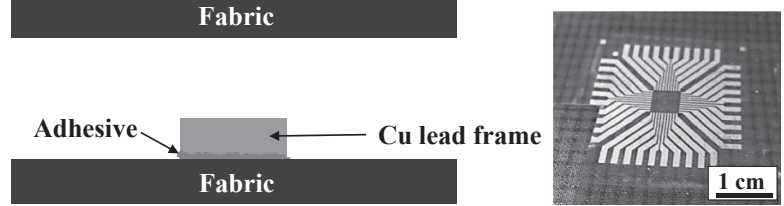

Fig. 3 Schematic illustrations of the fabrication process for a fabric substrate with optical micrographs at each process stage: (a) $\mathrm{Cu}$ lead frame adherent to the carrier film and protective film, (b) removal of the protective film, (c) bonding of the $\mathrm{Cu}$ lead frame to the fabric, and (d) fabric substrate completed with removal of the carrier film.

with dimensions of $320 \times 810 \mu \mathrm{m}^{2}$ underneath the $\mathrm{Cu} / \mathrm{Sn}$ bumps.

Though Au bumps have been commonly adapted for adhesive flip-chip bonding due to their good deformability and excellent oxidation resistance, ${ }^{20-22)}$ we used $\mathrm{Cu} / \mathrm{Sn}$ bumps instead. In addition to $\mathrm{Sn}$ being less expensive than $\mathrm{Au}, \mathrm{Sn}$ is softer and more deformable than Au. The micro Vickers hardnesses of the electrodeposited Sn and Au, which were measured with a load of $1 \mathrm{~N}$, were 5 and 34 , respectively. ${ }^{23)}$ Thus, it is plausible that a more solid contact could be obtained on a fabric substrate, where planarity or flatness is hardly ensured with a bump consisting of a $\mathrm{Sn}$ surface layer rather than an Au bump.

As illustrated in Fig. 3, which shows the optical micrographs of each process stage, a fabric substrate was fabricated by a transfer process of the $40-\mu \mathrm{m}$ thick $\mathrm{Cu}$ lead frame. The $\mathrm{Cu}$ lead frame, which was sandwiched between a carrier film and a protective film, was made by GP Inc. using a rolled $\mathrm{Cu}$ plate, polyester films, and an acrylic-based pressure-sensitive adhesive. After removing the protective film, the $\mathrm{Cu}$ lead frame with an adhesive layer on its top surface was flipped over together with a carrier film and positioned on the fabric, which was produced by D-I Tex Co. for protective clothing for firefighters (heat-resistant to high temperatures up to $200^{\circ} \mathrm{C}$ ). Then, bonding between the $\mathrm{Cu}$ lead frame and fabric was accomplished by pressing them together at $130^{\circ} \mathrm{C}$ for $5 \mathrm{~min}$ with a force of $1 \mathrm{kN}$. After detaching the carrier film from the $\mathrm{Cu}$ lead frame at room temperature, fabrication of the fabric substrate with the transferred $\mathrm{Cu}$ lead frame was complete. After dispensing a commercial ACA (Fujikura Kasei Co., Ltd. Type LS210FP3) or NCA (DELO-MONOPOX MK055) to the $\mathrm{Cu} / \mathrm{Sn}$ bumps of the Si chip, the chip was flip-chip bonded to the $\mathrm{Cu}$ lead frame of the fabric substrate using a Karl Suss Microtec flipchip bonder by holding at $160^{\circ} \mathrm{C}$ and $100 \mathrm{MPa}$ for $1 \mathrm{~min}$. An average contact resistance of the flip-chip joints was 
evaluated by measuring the daisy-chain resistance for different numbers of flip-chip joints with a Keithley 2000 multimeter. Both the ACA and NCA used in this study, of which the differential scanning calorimetry (DSC) results were illustrated in Fig. 4, were epoxy resin-based adhesives. The ACA exhibited a peak curing temperature at $395 \mathrm{~K}$, and the NCA showed its peak curing temperature at $400 \mathrm{~K}$. The ACA contains conductive particles made of polymer spheres of about $4 \mu \mathrm{m}$-diameter, which were electrodeposited with a thin Ni layer for electrical conduction and subsequently coated with a thin polymer layer for insulation. ${ }^{24,25)}$

We also flip-chip bonded the same $\mathrm{Si}$ chip to a rigid $\mathrm{Si}$ substrate for comparison. To fabricate a Si substrate, a 0.1$\mu \mathrm{m}$ thick $\mathrm{Ti}$ and $2-\mu \mathrm{m}$ thick $\mathrm{Cu}$ were sequentially sputtered on a $\mathrm{Si}$ wafer, which produced a daisy-chain configuration shown in Fig. 1(c). Then, a Si chip with $\mathrm{Cu} / \mathrm{Sn}$ bumps was flip-chip bonded to the Si substrate using ACA or NCA. Figures 5(a) and (b) illustrate our flip-chip specimens processed on a fabric and on a Si substrate, respectively.

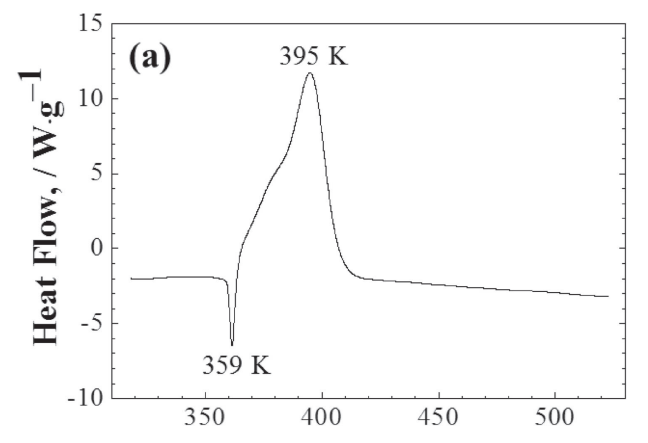

Temperature, $T$ / K

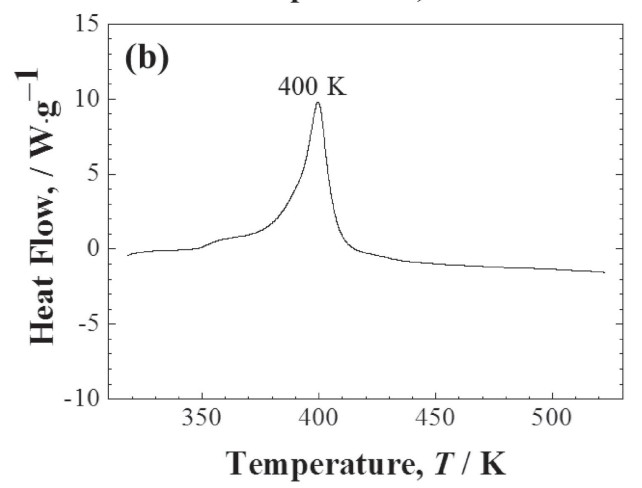

Fig. 4 Differential scanning spectroscopy curves of the (a) ACA and (b) NCA used for flip-chip bonding.

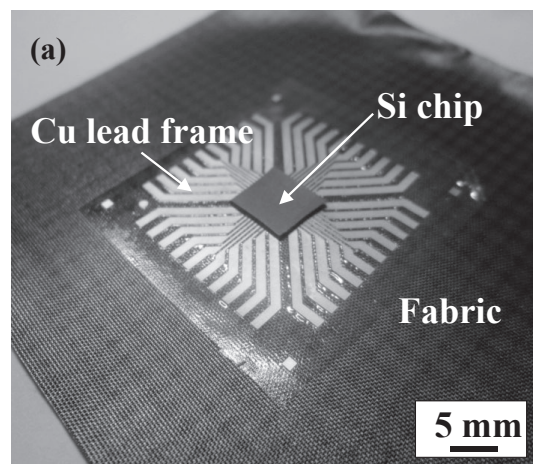

Fig. 5 Optical images of the specimens flip-chip bonded on (a) the fabric and (b) Si substrate.

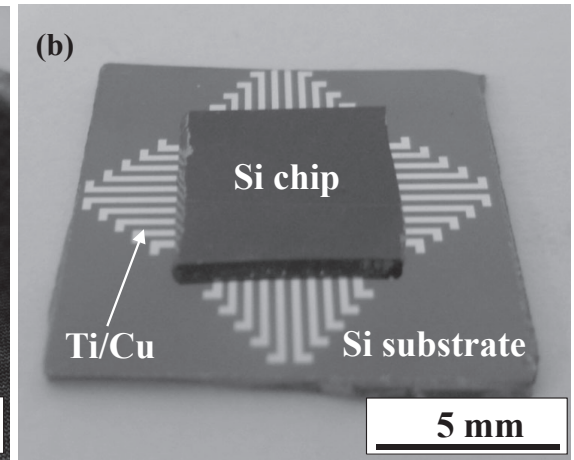

\section{Results and Discussion}

Figures 6 and Fig. 7 show the average contact resistances of the flip-chip joints processed on the reference Si substrate and fabric, respectively, as a function of the Sn thickness of the $\mathrm{Cu} / \mathrm{Sn}$ bump (total thickness of $15 \mu \mathrm{m}$ ). On the $\mathrm{Si}$

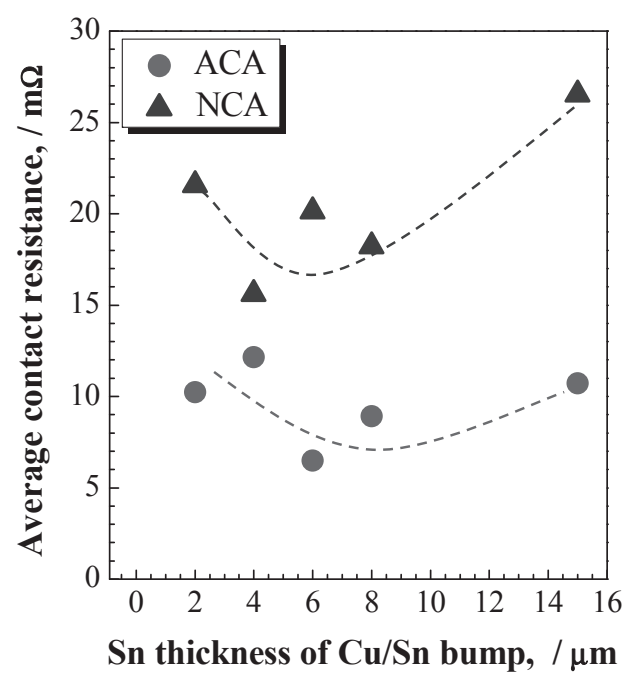

Fig. 6 Average contact resistance of the flip-chip joints processed on the Si substrate with ACA and NCA vs. the Sn thickness of the $\mathrm{Cu} / \mathrm{Sn}$ bumps.

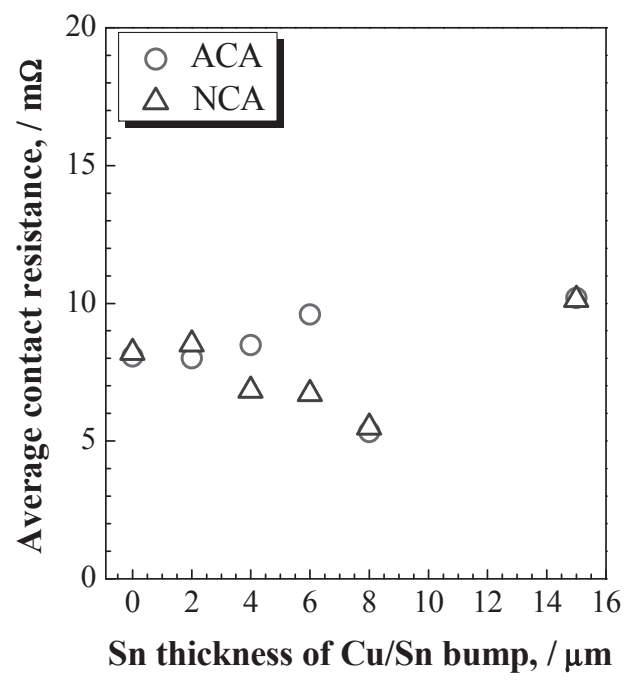

Fig. 7 Average contact resistance of the flip-chip joints processed on the fabric with ACA and NCA vs. the Sn thickness of the $\mathrm{Cu} / \mathrm{Sn}$ bumps. 


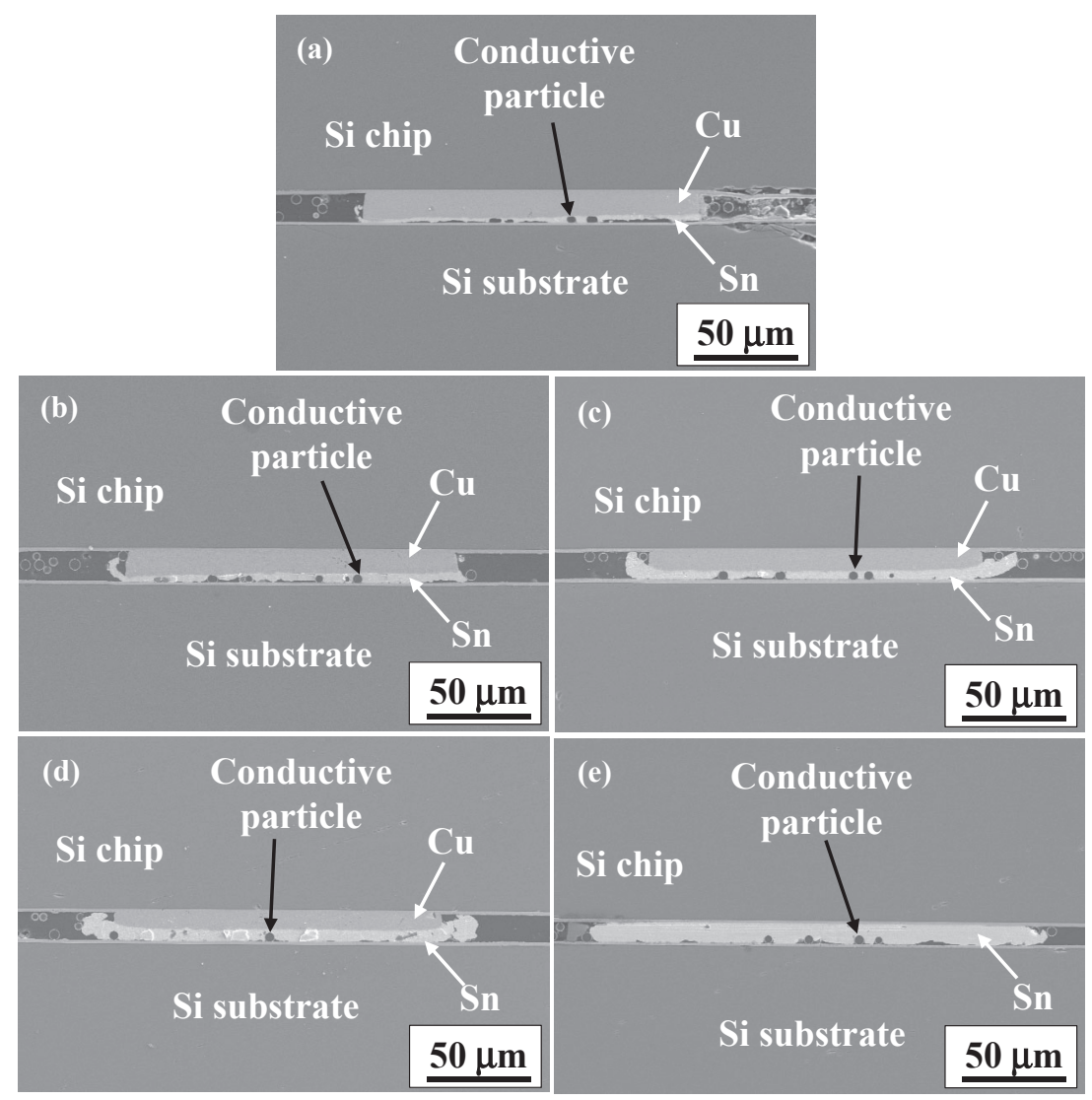

Fig. 8 Scanning electron micrographs of the flip-chip joints processed on the Si substrate with ACA using the chip bumps with (a) $13-\mu m$ thick $\mathrm{Cu} / 2-\mu \mathrm{m}$ thick $\mathrm{Sn}$, (b) $11-\mu \mathrm{m}$ thick $\mathrm{Cu} / 4-\mu \mathrm{m}$ thick Sn, (c) $9-\mu \mathrm{m}$ thick $\mathrm{Cu} / 6-\mu \mathrm{m}$ thick $\mathrm{Sn}$, (d) $7-\mu \mathrm{m}$ thick $\mathrm{Cu} / 8-\mu \mathrm{m}$ thick $\mathrm{Sn}$, and (e) $15-\mu \mathrm{m}$ thick $\mathrm{Sn}$.

substrates, the average contact resistances of the flip-chip joints bonded with the ACA were lower than those processed using the NCA for all the Sn thicknesses, which ranged from $0 \mu \mathrm{m}$ to $15 \mu \mathrm{m}$ for the $\mathrm{Cu} / \mathrm{Sn}$ bumps. However, on the fabric substrates, remarkably similar contact resistances were obtained for the flip-chip joints processed with both the ACA and the NCA regardless of the Sn thickness of the 15$\mu \mathrm{m}$ thick $\mathrm{Cu} / \mathrm{Sn}$ bumps. Clearly, the thickness and thus the resistance of the metallization lines formed by the $\mathrm{Cu}$ lead frame transferred to the fabric were extremely different from those of the sputter-deposited $\mathrm{Ti} / \mathrm{Cu}$ on the $\mathrm{Si}$ substrate. However, the average contact resistance of the flip-chip joints could be evaluated regardless of the resistance of the metallization lines by measuring the daisy-chain resistance vs. the different number of flip-chip joints. ${ }^{18,19,26)}$ Indeed, quite similar values of contact resistance were evaluated for the flip-chip joints processed with the ACA on both the Si substrate and the fabric despite their circuit metallizations being extremely different from each other.

Cross-sectional scanning electron micrographs of the flipchip joints processed with the ACA and the NCA on a reference $\mathrm{Si}$ substrate are illustrated in Figs. 8 and 9, respectively. Microstructures of the flip-chip joints formed with the ACA and the NCA on fabric are also shown in Figs. 10 and 11, respectively. Although the 2.1- $\mu \mathrm{m}$ thick $\mathrm{Ti} / \mathrm{Cu}$ metallization on the rigid, undeformable Si substrate remained flat, even underneath the flip-chip joints, the $40-\mu \mathrm{m}$ thick $\mathrm{Cu}$ lead frame on the fabric substrate was deformed in a curve-like manner in the local area underneath the chip bumps that were bonded using both the ACA and the NCA. Such microstructural dependency of the flip-chip joints upon a substrate would explain the contact-resistance behavior, as shown in Figs. 6 and 7, related to the adhesive and substrate.

The contact resistance $R_{\mathrm{c}}$ of a flip-chip joint is composed of the bump resistance $R_{\mathrm{b}}$ and flip-chip interface resistance $R_{\mathrm{i}}$ between a chip bump and substrate pad. Because the electrical resistivities of $\mathrm{Sn}$ and $\mathrm{Cu}$ were $1.09 \times 10^{-7} \Omega \cdot \mathrm{m}$ and $1.68 \times 10^{-8} \Omega \cdot \mathrm{m}$ at $20^{\circ} \mathrm{C}$, respectively, ${ }^{27)}$ the bump resistances $R_{\mathrm{b}}$ were calculated to be $0.05 \mathrm{~m} \Omega$ and $0.008 \mathrm{~m} \Omega$ for a $\mathrm{Sn}$ bump and $\mathrm{Cu}$ bump with a $15-\mu \mathrm{m}$ thickness and dimensions of $150 \times 220 \mu \mathrm{m}^{2}$, respectively. Comparing such small bump resistances $R_{\mathrm{b}}$ of 0.05 and $0.008 \mathrm{~m} \Omega$ with the measured contact resistance $R_{\mathrm{c}}$ of 5.3-26.5 $\mathrm{m} \Omega$, as shown in Figs. 5 and 7, the contact resistance $R_{\mathrm{c}}$ of the flip-chip joint was attributed mostly to the flip-chip interface resistance $R_{\mathrm{i}}$ with a negligible contribution from the bump resistance $R_{\mathrm{b}}$. As shown in Figs. 8-11, the overall size of the flip-chip bonded $\mathrm{Sn}$ bumps became much larger due to severe $\mathrm{Sn}$ deformation than those of the $\mathrm{Cu} / \mathrm{Sn}$ and $\mathrm{Cu}$ bumps regardless of the substrate and adhesives used for the flipchip process. However, the contact resistances of the flip-chip joints formed with the Sn bumps were larger than those for other flip-chip joints fabricated with the $\mathrm{Cu} / \mathrm{Sn}$ or $\mathrm{Cu}$ bumps (Figs. 6 and 7), which implies that a larger flip-chip interface resistance of the Sn-bump joints, even with severe plastic deformation of the $\mathrm{Sn}$ bumps, which enlarges their size. 


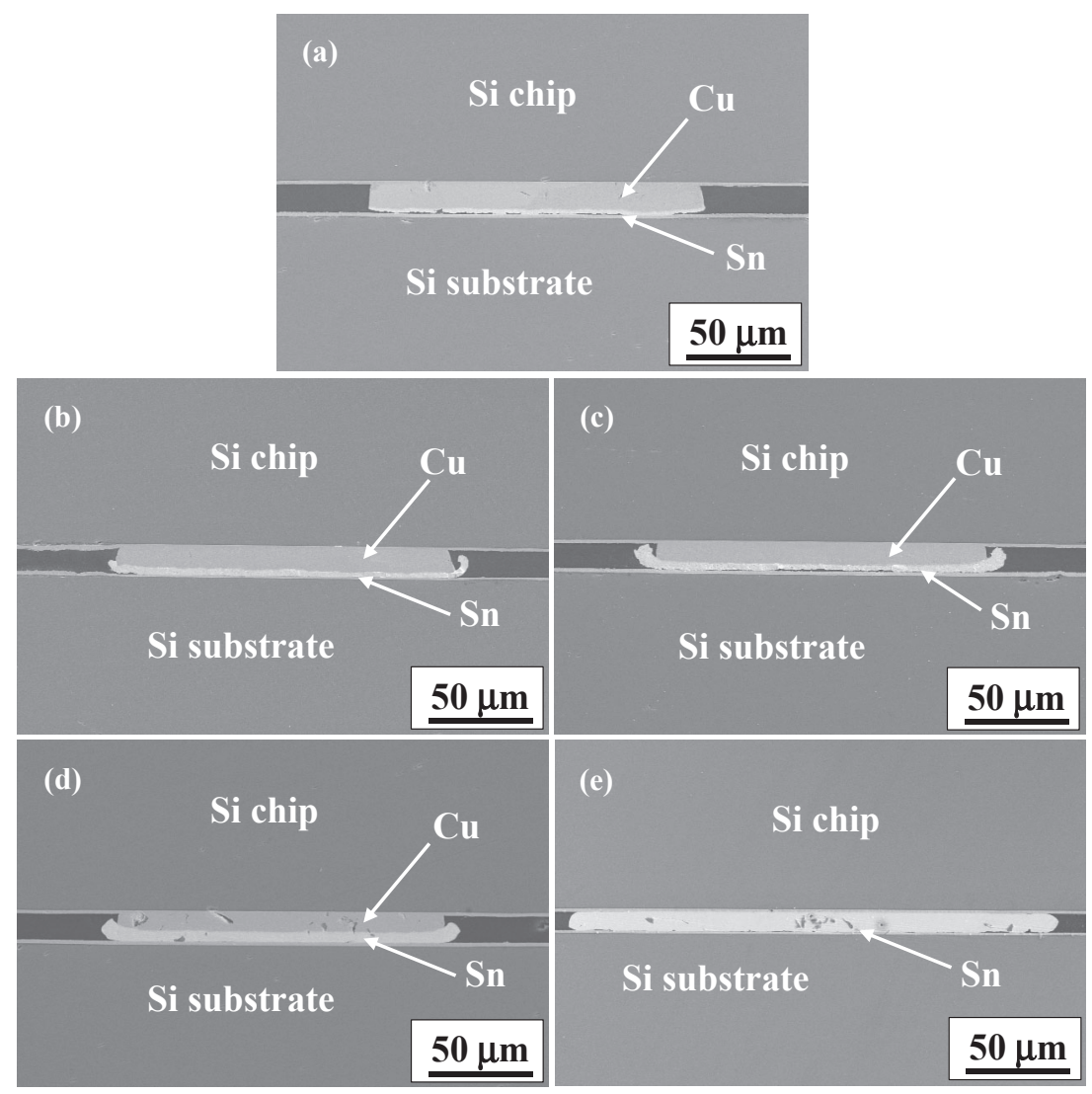

Fig. 9 Scanning electron micrographs of the flip-chip joints processed on the Si substrate with NCA using the chip bumps with (a) $13-\mu \mathrm{m}$ thick $\mathrm{Cu} / 2-\mu \mathrm{m}$ thick $\mathrm{Sn}$, (b) $11-\mu \mathrm{m}$ thick $\mathrm{Cu} / 4-\mu \mathrm{m}$ thick Sn, (c) $9-\mu \mathrm{m}$ thick $\mathrm{Cu} / 6-\mu \mathrm{m}$ thick $\mathrm{Sn}$, (d) $7-\mu \mathrm{m}$ thick $\mathrm{Cu} / 8-\mu \mathrm{m}$ thick $\mathrm{Sn}$, and (e) $15-\mu \mathrm{m}$ thick $\mathrm{Sn}$.

Improper contact formation at the flip-chip interface of the $\mathrm{Sn}$ bumps, particularly for the flip-chip joints formed by the NCA on the Si substrate, could be caused by the rough surface of the electroplated Sn. The average surface roughnesses of the electroplated $\mathrm{Sn}$ were evaluated to be $1.1 \mu \mathrm{m}$ and $1.6 \mu \mathrm{m}$ at $\mathrm{Sn}$ thicknesses of $8 \mu \mathrm{m}$ and $15 \mu \mathrm{m}$, respectively. ${ }^{8)}$ Large surface protrusions of the $15-\mu \mathrm{m}$ thick $\mathrm{Sn}$ bumps prevented proper contact between the Sn bumps and substrate pads, which resulted in a larger flip-chip interface resistance $R_{\mathrm{i}}$ and subsequently, a larger contact resistance $R_{\mathrm{c}}$. Although the surface roughness is small for a $\mathrm{Cu} / \mathrm{Sn}$ bump with a thin $\mathrm{Sn}$ layer or the $\mathrm{Cu}$ bump without a Sn layer, the plastic deformability of such bump surface to be flattened during flip-chip bonding was limited. Then the adhesive entrapped between the protrusions of the bump surface could not be easily squeezed out from the interface, making the contact resistance increase. In Fig. 6, such tendency of contact-resistance increase with reducing the Sn-layer thickness to a certain level is clear observed.

In Fig. 6, the NCA-processed joints on the Si substrate exhibited large contact resistances compared with those of the ACA-bonded joints. For a chip-on-glass (COG) process using Sn bumps and NCA, a considerable amount of NCA was entrapped within an interface area of approximately $7-20 \%$ of the COG joint due to the surface roughness of the Sn bumps, ${ }^{28)}$ and the interface resistance $R_{\mathrm{i}}$ and subsequently, the contact resistance increased with increasing amounts of entrapped NCA. In our previous work, ${ }^{8)}$ we also reported that the contact resistance of the flip-chip joints formed with NCA on a rigid $\mathrm{Si}$ substrate was dependent upon the degree of surface roughness of the $\mathrm{Cu} / \mathrm{Sn}$ bumps. Figure 12(a) clearly shows the NCA entrapped at the interface gap between the rough surface valley of a Sn bump and a flat substrate pad. The lower contact resistance of the ACA-bonded joints on a Si substrate than that of the NCA-processed joints could be attributed to the entrapping of conductive particles of the ACA into the interface gap between a rough chip bump and a flat substrate pad, as illustrated in Fig. 12(b).

In comparison with those processed on the Si substrates, both the ACA- and NCA-bonded joints exhibited extremely similar contact resistances on the fabric (Fig. 7). With the soft, deformable nature of the fabric, the $\mathrm{Cu}$ lead frame was deformed in a curve-like manner in the local area underneath the chip bumps, where the actual flip-chip load was selectively applied, which resulted in close contact between the chip bumps and $\mathrm{Cu}$ lead frame. Then, the protruded surface of the $\mathrm{Cu} / \mathrm{Sn}$ bumps was severely compressed and flattened via the entrapped NCA being squeezed out. Thus, additional close contact at the flip-chip interface with less entrapped NCA could facilitate lower contact resistances on the fabric than those obtained with NCA on the rigid, undeformable Si substrate. With minimal entrapment of the adhesive polymer at the flip-chip interface processed on the fabric, conductive particles of ACA are not considerably effective for further contact improvement, which results in similar contact resistances for both the NCA- and ACA- 

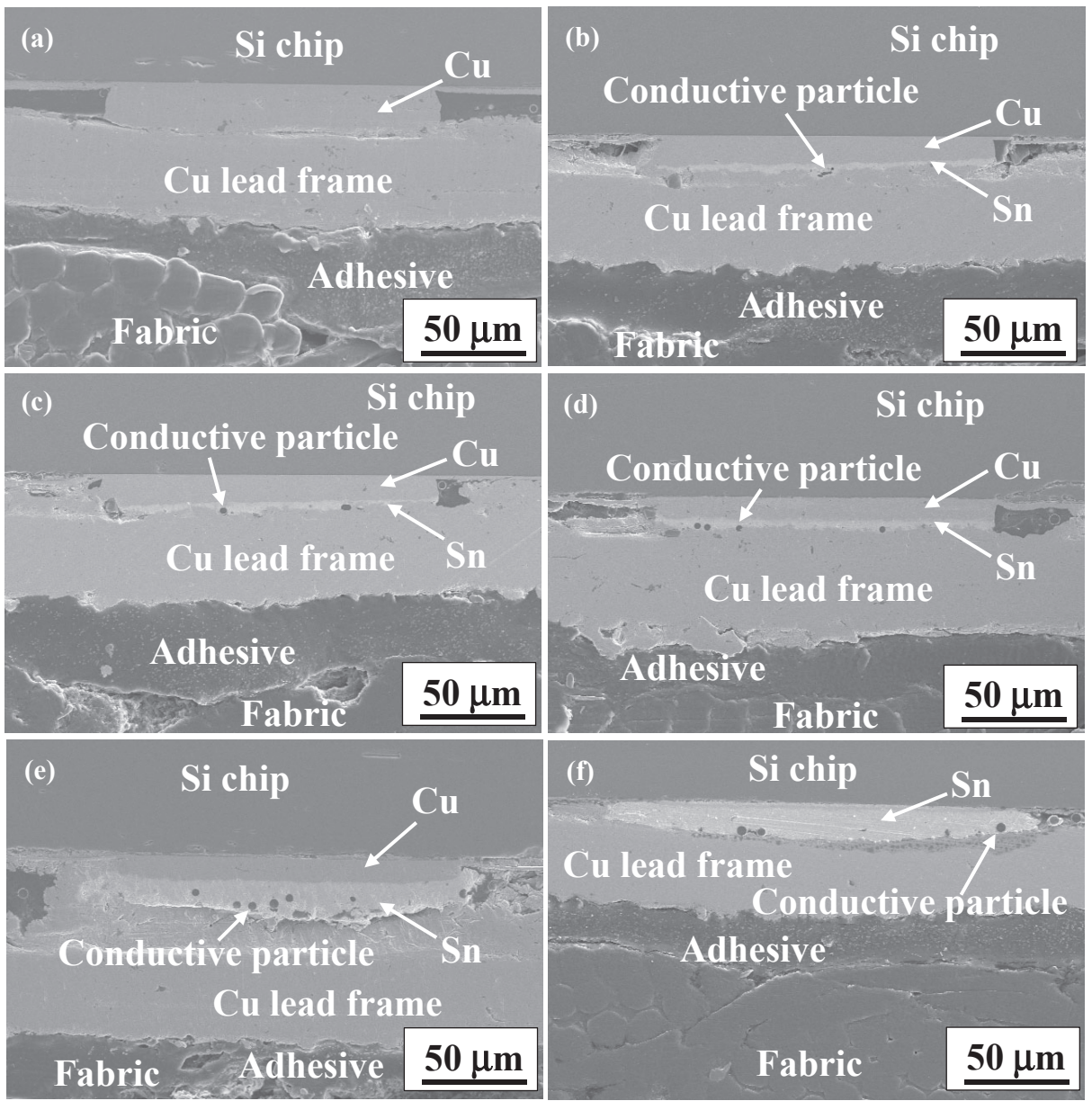

Fig. 10 Scanning electron micrographs of the flip-chip joints processed on the fabric with ACA using the chip bumps with (a) 15 - $\mu$ m

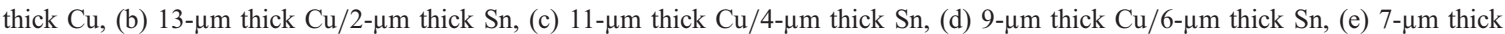
$\mathrm{Cu} / 8-\mu \mathrm{m}$ thick $\mathrm{Sn}$, and (f) $15-\mu \mathrm{m}$ thick $\mathrm{Sn}$.

bonded joints on fabric. From the viewpoint of contact resistance, ACA would be more appropriate to use than NCA to obtain a flip-chip bonding with a low contact resistance on a conventional rigid substrate, such as a printed circuit board. However, on a fabric substrate for smart textile applications, a flip-chip process with NCA is highly recommended over ACA due to its advantages of not only a contact resistance as low as that of the ACA-bonded flip-chip joints but also its lower cost.

As shown in Fig. 11, the $\mathrm{Sn}$ bumps and the $\mathrm{Cu} / \mathrm{Sn}$ bumps with a Sn layer thicker than $6 \mu \mathrm{m}$ were plastically deformed to match to the curvedly deformed $\mathrm{Cu}$ lead-frame on the fabric. Due to the high stiffness of $\mathrm{Cu}$, however, the $\mathrm{Cu}$ bumps and the $\mathrm{Cu} / \mathrm{Sn}$ bumps with a $\mathrm{Sn}$ layer thinner than $4 \mu \mathrm{m}$ could not be fully deformed to fit to the deformed contour of the $\mathrm{Cu}$ lead-frame on the fabric, leaving the center region of the flip-chip interface uncontacted and filled with the NCA. This could explain the contact-resistance increase in Fig. 7 for the flip-chip joints processed with $\mathrm{Cu} / \mathrm{Sn}$ bumps with a thin $\mathrm{Sn}$ layer or $\mathrm{Cu}$ bumps without a $\mathrm{Sn}$ layer. As the fabric is soft, partial restitution of the deformed $\mathrm{Cu}$ lead frame could occur after flip-chip bonding, especially processed especially with stiffer chip bumps, which would also affect the contact-resistance increase with reducing the $\mathrm{Sn}$ layer thickness of the $\mathrm{Cu} / \mathrm{Sn}$ bumps to a certain level. As the contact resistance of the flip-chip joints is determined by the surface roughness and deformation capacity of the bump as well as the restitution of the deformed $\mathrm{Cu}$ lead frame, the optimum configuration of the $\mathrm{Cu} / \mathrm{Sn}$ bump for a minimum contact resistance could be the 7- $\mu$ m-thick $\mathrm{Cu}$ and $8-\mu \mathrm{m}$ thick $\mathrm{Sn}$ on the fabric substrate.

\section{Conclusion}

For application in smart textiles, flip-chip bonding was processed using ACA and NCA on a heat-resistant fabric, and the average contact resistance of the flip-chip joints was evaluated by varying the $\mathrm{Cu}$ and $\mathrm{Sn}$ thicknesses of the $\mathrm{Cu} / \mathrm{Sn}$ bumps, which had a total thickness of $15 \mu \mathrm{m}$. For comparison, the contact resistance of the flip-chip joints formed with NCA and ACA on a $\mathrm{Si}$ substrate was also measured as a reference. Although the contact resistances of 15.6-26.5 $\mathrm{m} \Omega$ for the NCA-processed joints were different from those of $6.5-12.2 \mathrm{~m} \Omega$ for the ACA-bonded joints on the reference Si substrate, extremely similar contact resistances of 5.3-10.2 $\mathrm{m} \Omega$ and 5.5-10.1 $\mathrm{m} \Omega$ were obtained on the fabric for the flip-chip joints fabricated with both ACA and NCA, respectively. Additionally, the contact resistances of the flipchip joints processed with ACA on either the fabric or $\mathrm{Si}$ substrate were quite similar to each other. Although the 

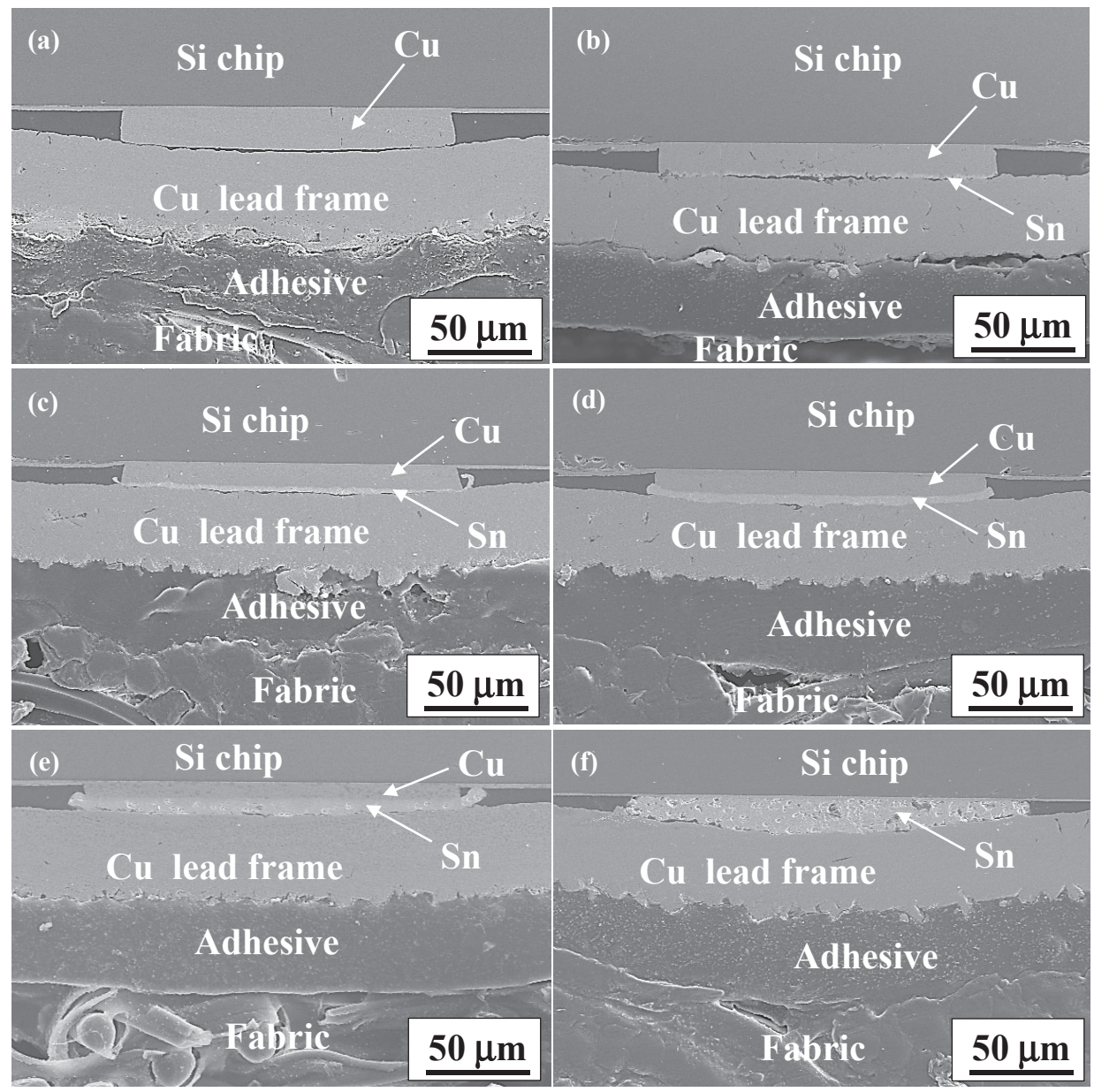

Fig. 11 Scanning electron micrographs of the flip-chip joints processed on the fabric with NCA using the chip bumps with (a) $15-\mu \mathrm{m}$ thick $\mathrm{Cu}$, (b) $13-\mu \mathrm{m}$ thick $\mathrm{Cu} / 2-\mu \mathrm{m}$ thick Sn, (c) $11-\mu \mathrm{m}$ thick $\mathrm{Cu} / 4-\mu \mathrm{m}$ thick Sn, (d) $9-\mu \mathrm{m}$ thick $\mathrm{Cu} / 6-\mu \mathrm{m}$ thick Sn, (e) $7-\mu \mathrm{m}$ thick $\mathrm{Cu} / 8-\mu \mathrm{m}$ thick Sn, and (f) $15-\mu \mathrm{m}$ thick Sn.
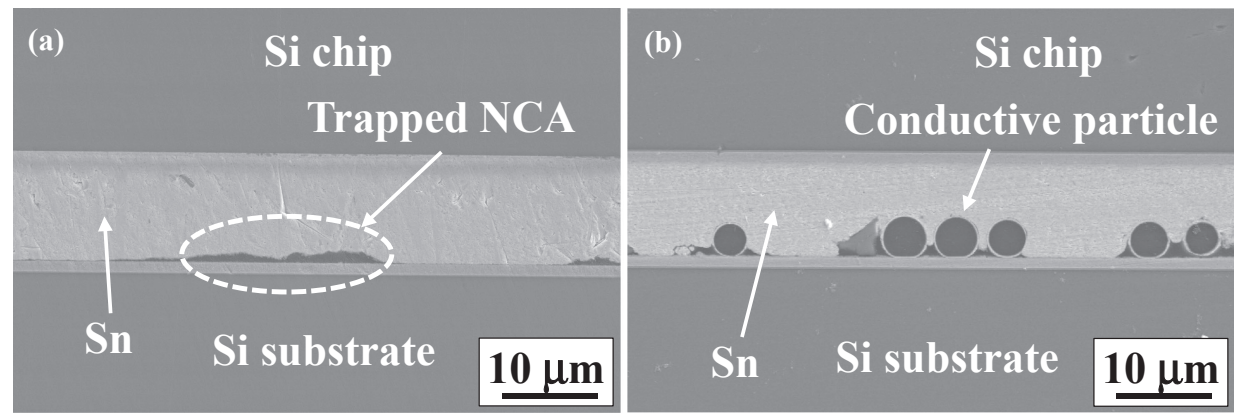

Fig. 12 Scanning electron micrographs of the flip-chip joints processed with the $15-\mu \mathrm{m}$ thick Sn bumps on an Si substrate showing (a) the NCA entrapped at the flip-chip interface and (b) the conductive particles of the ACA entrapped at the flip-chip interface.

circuit metallization on the rigid, undeformable Si substrate remained flat underneath the flip-chip joints, the $\mathrm{Cu}$ lead frame on the fabric was deformed in a curve-like matter in the local area underneath the flip-chip joints due to the soft, deformable nature of the fabric. Such a microstructural difference of the flip-chip joints would explain the contactresistance behavior related to the substrates and adhesives.

\section{Acknowledgement}

This work was supported by the ICT R\&D program of MSIP/KEIT of Korea [14-824-11-004, Development of
Transformational and Slap-on Wearable Device and $\mathrm{UI} / \mathrm{UX}]$.

\section{REFERENCES}

1) M. Stoppa and A. Chiolerio: Sensors 14 (2014) 11957-11992.

2) L. M. Castano and A. B. Flatau: Smart Mater. Struct. 23 (2014) 053001 .

3) J. Berzowska: Textile 3 (2005) 58-75

4) S. Wagner, E. Bonderover, W. B. Jordan and J. C. Strum: Int. J. High Speed Electron. Syst. 12 (2002) 391-399.

5) T. Linz, R. Vieroth, C. Dils, M. Koch, T. Braun, K. F. Becker, C. Kallmayer and S. M. Hong: Adv. Sci. Technol. 60 (2008) 85-94. 
6) S. Park and S. Jayaramin: Mater. Res. Bull. 28 (2003) 585-591.

7) J. Y. Choi and T. S. Oh: J. Microelectron. Packag. Soc. 20 (2013) 1723.

8) J. Y. Choi and T. S. Oh: J. Electron. Mater. 43 (2014) 4464-4471.

9) E. R. Post, M. Orth, P. R. Russo and N. Gershenfled: IBM Systems J. 39 (2000) 840-860.

10) S. Mondal: Appl. Thermal Eng. 28 (2008) 1536-1550.

11) D. Zhang, M. Miao, H. Niu and Z. Wei: ACS Nano 8 (2014) 45714579.

12) D. Gandhi, D. Gadodia, S. Kadam and H. Narula: Int. J. Eng. Trends Technol. 16 (2014) 373-376.

13) Y. J. Yun, W. G. Hong, W. J. Kim, Y. Jun and B. H. Kim: Adv. Mater. 25 (2013) 5701-5705.

14) D. Marculescu, R. Marculescu, N. H. Zamora, P. Stanley-Marbell, P. K. Khosla, S. Park, S. Jayaraman, S. Jung, C. Lauterbach, W. Weber, T. Kirstein, D. Cottet, Z. Grzyb, G. Troster, M. Jones, T. Martin and Z. Nakad: Proc. IEEE 91 (2003) 1995-2018.

15) Y. Kim, H. Kim and H. J. Yoo: IEEE Trans. Adv. Packag. 33 (2010) 196-205.

16) S. C. Kim and Y. H. Kim: Current Appl. Phys. 13 (2013) S14-S25.

17) M. J. Yim and K. W. Paik: Electron. Mater. Lett. 2 (2006) 183-194.
18) T. S. Oh, K. Y. Lee and H. J. Won: IEEE Trans. Comp. Packag. Technol. 32 (2009) 909-914.

19) J. Y. Choi and T. S. Oh: Korean J. Met. Mater. 50 (2012) 785-792.

20) M. J. Yim, J. S. Hwang, W. Kwon, K. W. Jang and K. W. Paik: IEEE Trans. Electron. Packag. Manuf. 26 (2003) 150-155.

21) S. T. Lu and W. H. Chen: IEEE Trans. Adv. Packag. 33 (2010) 702712.

22) Z. G. Chen and Y. H. Kim: Displays 27 (2006) 130-135.

23) K. J. Shin and T. S. Oh: J. Electron. Mater. (2015) doi:10.1007/s11664015-3647-2.

24) M. A. Uddin and H. P. Chan: Rev. Adv. Mater. Sci. 27 (2011) 151-157.

25) Y. C. Chan and D. Y. Luk: Microelectron. Reliab. 42 (2002) 11951204.

26) T. S. Oh, K. Y. Lee, Y. H. Lee and B. Y. Jung: Met. Mater. Int. 15 (2009) 479-485.

27) J. P. Schaffer, A. Saxena, S. D. Antolovich, T. H. Sanders and S. B. Warner: The Science and Design of Engineering Materials, (Richard D. Irwin, Inc., Chicago, 1995) p. 445.

28) S. M. Lee, B. G. Kim and Y. H. Kim: Mater. Trans. 49 (2008) 21002106 . 